\title{
An Introduction: COVID-19 Pandemic and Academic Leadership
}

\author{
Wadim Strielkowski* \\ Prague Institute for Qualification Enhancement \\ Trnkovo náměstí 1112/2, 15200 Prague \\ Czech Republic \\ e-mail: strielkowski@prizk.cz \\ Jing Wang \\ School of Management \\ Shandong University \\ 27 Shandu Nanlu Jinan, 250100 Shandong \\ People's Republic of China \\ e-mail: jingwang@sdu.edu.cn
}

\begin{abstract}
In general, any form of leadership, either social, economic, or academic is determined by the quick response to the social and economic changes. The leaders are the ones who seek to exploit the creative destruction brought about by the unexpected events.

The events of the recent months have changed many things. When the ICSEAL 2019 conference was held in Prague in December 2019, the COVID-19 coronavirus pandemic was just starting in China. Very soon it spread all over the world and forever changed our perception of the globalisation and digitalisation. As many countries all around the world are currently in lockdown, international travel came to a halt, and businesses and industries are struggling to stay afloat, new opportunities and challenges emerge. One of the most interesting impacts of the pandemic can be observed in the higher education where the new leading technologies are launching its digital revolution.

This paper constitutes a short introduction to the Proceedings of the $6^{\text {th }}$ International Conference on Social, economic, and academic leadership (ICSEAL 2019) that was organized by the Prague Institute for Qualification Enhancement in Prague, Czech Republic, on the $13^{\text {th }}-14^{\text {th }}$ of December 2019 and accommodated together professors, researchers, graduate students, and practitioners. It briefly polemises over the implications of the COVID-19 pandemic for the academic leadership and summarizes its main provisions.
\end{abstract}

Keywords: leadership, academic leadership, COVID-19, higher education, pandemic

\section{Introduction}

One would never get bored with exploring and studying leadership. The topic has so many angles and dimensions that it would never drain out of ideas and inspiration. Moreover, it can be used as a prism for studying other subjects and processes (Floyd and Fung 2017).

These Proceedings originated from the materials of the international conference that took place in Prague, Czech Republic, on the $13^{\text {th }}$ and $14^{\text {th }}$ of December 2019 (see PRIZK 2020). The ICSEAL 2019 conference was held as yet another conference in the line of successive events following the $1^{\text {st }}$ International Conference "Social, economic, and academic leadership for the future sustainable development of business and education" which was organised in Prague three years ago, in September 2017 (see Strielkowski and Chigisheva 2018). Subsequent events and conferences on the same topic held in 2018 and 2019 also resulted in interesting and widely cited Proceedings published by Atlantis Press (see e.g. Strielkowski 2018; or Strielkowski 2019).

We are very happy to state that the $6^{\text {th }}$ International Conference on Social, economic, and academic leadership once again succeeded in bringing together academics and stakeholders from the fields of business, economics, education, social sciences, psychology, anthropology, pedagogy, history, and international relations. Together, we managed to create an interesting volume of Proceedings that is worth reading and consulting for everyone interested in leadership in all its forms.

In this short Introduction, we would like to react to the current COVID-19 pandemic and analyse some of the hardships it brought upon academia and on the higher education. No one even suspected or envisaged the size and the magnitude of the coronavirus pandemic and its impacts upon the world's economies in the times of our Conference. The pandemic emerged amazingly fast and apart from all its obvious negative effects also brought some interesting implications in the field of academic leadership. In this introductory piece, we reflect on these implications which might mean what we call "the digital revolution" in academia and higher education. 


\section{Conference and main tracks}

The $6^{\text {th }}$ International Conference on Social, economic, and academic leadership (ICSEAL 2019) organised in Prague by the Prague Institute for Qualification Enhancement in December 2019 consisted of keynote presentations, oral presentations and poster presentations held in sessions on specific topics. All presentations were met with a great enthusiasm and interests. Long discussions and debates followed.

After a long and cumbersome selection of papers submitted to our conference, those that were found to be in accord with rigorous academic and ethical publishing standards, underwent a double-blind peer review. Overall, 79 papers were selected for publication in a form of online proceedings with Atlantis Press international publisher. The selected papers represent several fields. However, all of them have one unifying topic - leaders and leadership.

All the papers were collected and put into the six Conference tracks following thematically close areas which helped the organizers to order the contributions in a logical and arranged manner. The overall final structure of the Proceedings from the ICSEAL 2019 Conference can be presented as arranged along the six main tracks listed below:

- Leadership in social sciences

- Leadership in business and economics

- Leadership in science and education

- Leadership and sustainability

- Digital and information leadership

- Leadership in international relations and political sciences

Apart from all the above, it was really a pleasure for the conference organisers to host an international mix of outstanding contributors from several countries including China, Czech Republic, Georgia, Russian Federation, and Ukraine. Most papers in these Proceedings are interdisciplinary and were written by several co-authors. This helps to maintain the multidisciplinary nature of our Proceedings.

\section{Online and digital university}

The COVID-19 pandemic started as some other seasonal flu in the Chinse city of Wuhan in December 2019, just around the time our Conference was held in Prague. Spreading very fast in Wuhan and then in the other areas of China it soon became a global issue. However, when it surfaced in Italy and in other European Union (EU) countries in February 2020, it started spreading quickly all around the world and soon was declared to be a pandemic.

Currently, with major world economies still in shutdown, people practicing social distancing and selfisolation, and the global travel coming to almost zero, COVID-19 pandemic showed us many weaknesses of our global capitalist system. Some people say that the pandemic put an end to globalisation as we know it (Mas-Coma et al. 2020).

With all the impacts brought about by the pandemic, one of the most profound ones is the impact on academia and higher education. In the recent years, both were undergoing many profound changes, but the progress was quite slow. Moreover, the major push factor that would lead to the shift of perception about how the university of the $21^{\text {st }}$ century should be organised and managed was missing. Now, it appears that the COVID-19 pandemic might be this decisive push factor.

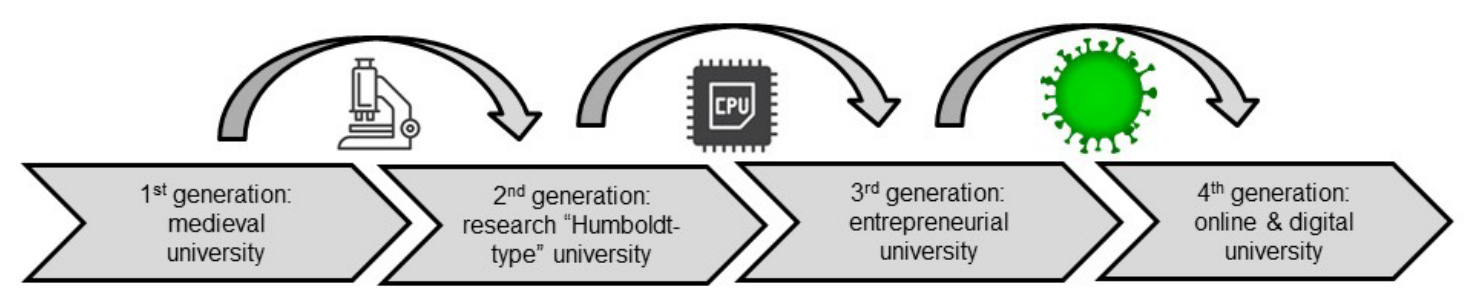

Fig. 1. Four generations of universities and the transition to the University 2.0 Source: Own results

Wissema (2009) describes the evolution of universities through the transition encompassing the three main generations. The transition went on in several stages from the medieval universities (such as Sorbonne or the University of Bologna) to the research universities (Humboldt-type universities), and finally to the high-tech, science and technology driven entrepreneurial universities (the best example would be the University of 
Cambridge). With regard to that evolution, Strielkowski (2020) adds that nowadays we are starting the $4^{\text {th }}$ generation of universities which can be called "online and digital university" (see Figure 1 above).

Digitalisation in higher education allows streaming lectures on Zoom, Google Meet, or WebEx. It allows professors and their students to meet in the virtual environments. However, not everyone is ready for these changes. Many young people who were born with smartphones clutched in their fists and who would rather live without running water or electricity than without Internet, often tend to prefer being lectured by real professors in the real classrooms. Habitually, it might be just a matter of custom, but it appears that most likely it might be an issue of laziness and procrastination (see Strielkowski et al. 2020). The necessity of doing the lectures, exams, graduations, and defences using Internet and online tools might help to break these customs allowing to open the students' and professors' minds to the online education.

It is quite a paradox that all these changes happened without a specific leadership or leaders leading the way. Academic leadership might benefit from the COVID-19 pandemic in a way that no one envisaged before. Because of the coronavirus restrictions tones or red tape are being overruled overnight and things that would be impossible or next to impossible to implement in academia and the higher education due to the administrational rules and codes are being implemented in a matter of days. This is a clear example of the Schumpeter's creative destruction that helps to make a leap to the new and unprecedented perception of how the universities worldwide might proceed to function after the pandemic is over.

\section{Conclusions and implications}

All in all, it becomes obvious that our Proceedings that emerged from the $6^{\text {th }}$ International Conference on Social, economic, and academic leadership (ICSEAL 2019) achieved a remarkable task of producing high-quality multidisciplinary research from many fields of social sciences, humanities, business studies, mathematics, computer sciences and legal studies, just to name a few. We hope that it would make an interesting read for academics and practitioners worldwide.

Our Proceedings present the opinions of academics and stakeholders from six countries but have much larger potential and reach. This is due to a number of reasons. First, they present many interesting case studies that might become an inspiration for other academics and practitioners all around the world. Second, they address very timely issues such as, for example, digitalisation or globalisation viewed through the magnifying glass of leadership. Third, they blend practical approach with theoretical viewpoints which makes them useful as blueprints. Our Proceedings can be of interest for the researches, academics, and businessmen. In addition, they might also be useful for the members of the general public, journalists, or politicians seeking for the answers to some of their pressing questions.

It also should be mentioned that the topic of leadership is gaining the particular importance in the difficult times of the COVID-19 pandemic when humanity has to face many unusual challenges. In the times of troubles, leaders as well as leading solutions and approaches are in great demand. In this paper, we touched upon the issue of leadership in academia and the higher education as a result of digital revolution triggered off by the coronavirus pandemic. This constitutes a remarkably interesting topic that needs to be investigated and pursued in the followup further research.

\section{References}

Floyd A, Fung D (2017) Focusing the kaleidoscope: exploring distributed leadership in an English university. Studies in higher education 42(8):1488-1503. doi: 10.1080/03075079.2015.1110692

Mas-Coma S, Jones MK, Marty AM (2020) COVID-19 and globalization. One Health 9. doi: 10.1016\%2Fj.onehlt.2020.100132

PRIZK (2020) Website of the $6^{\text {th }}$ International Conference on Social, economic, and academic leadership (ICSEAL 2019). https://www.prizk.cz/en/icseal-vi-2019. Accessed 09 May 2020

Strielkowski W (2020) COVID-19 Pandemic and the Digital Revolution in Academia and Higher Education. Preprints 2020040290. doi: 10.20944/preprints202004.0290.v1

Strielkowski W (ed.) Proceedings of the $2^{\text {nd }}$ International Conference on Social, Economic and Academic Leadership (ICSEAL 2018), $1^{\text {st }}$ edn. (Atlantis Press, ASSEHR, vol. 217, ISSN 2352-5398, 2018). https://www.atlantis-press.com/proceedings/icseal-18. Accessed 09 May 2020 
Strielkowski W (ed.) Proceedings of the $4^{\text {th }}$ International Conference on Social, Business, and Academic Leadership (ICSBAL 2019), $1^{\text {st }}$ edn. (Atlantis Press, ASSEHR, vol. 359, ISSN 2352-5398, 2019). https://www.atlantis-press.com/proceedings/icsbal-19. Accessed 09 May 2020

Strielkowski W, Chigisheva O (eds.) Leadership for the Future Sustainable Development of Business and Education, $1^{\text {st }}$ edn. (Springer Proceedings in Business and Economics. Springer, Cham, 2018), 672 p. doi: 10.1007/978-3-319-74216-8

Strielkowski W, Volchik V, Maskaev A, Savko P (2020) Leadership and Effective Institutional Economics Design in the Context of Education Reforms. Economies 8(2):27. doi: 10.3390/economies 8020027

Wissema J, Towards the third-generation university: Managing the university in transition, $1^{\text {st }}$ edn. (Edward Elgar Publishing, UK, 2009), 252 p. 